\title{
$=\mathrm{T} R A M A=$
}

\section{REMEMORAR É PRECISO: ECOS DA ESCRAVIDÃO NOS POEMAS DE FÁTIMA TRINCHÃO}

\author{
ELIANA SALES VIEIRA (UFBA) ${ }^{1}$
}

\begin{abstract}
RESUMO: O presente texto propõe-se a analisar a produção literária da escritora negra baiana Fátima Trinchão, como uma prática de (r)existência, com base nos estudos sobre feminismo negro a partir de uma leitura decolonial. Para compor tal reflexão, foram selecionados poemas da escritora que rememoram a escravidão, período no qual o corpo das mulheres negras foi destituído de mente (HOOKS, 1995), sendo sistematicamente violentado pelos senhores brancos. A partir dessa análise, pretende-se pensar como essa escrita (re)significa as memórias da escravidão, entendendo que esse ato de rememoração reveste-se, conforme aponta Márcia dos Santos (2007), de uma intencionalidade que, para além da perspectiva de "conhecer o passado", delimita também ações e reações necessárias ao exercício político, marcando identidades e lutas.
\end{abstract}

PALAVRAS-CHAVE: Fátima Trinchão. Escrita feminina negra. Decolonialidade.

ABSTRACT: The following text aims to analyze the literary production of the black author, born in Bahia,Fátima Trinchão, as a practice of r(existence), based on the studies on black feminism through decolonial reading. For such selection, there were chosen poems from the referred author, which look back at slavery, when black women's bodies were deprived of mind (HOOKS, 1995), and they were systematically raped by white masters. Through this analysis, it is intended to think how this writing (re) signify memories from slavery, by understanding that this remembering takes on, as pointed out by Márcia dos Santos (2007), an intentionality which, beyond the perspective of " getting to know the past time", also delimits actions and reactions that are necessary for the political exercise, imprinting identities and fights.

KEYWORDS: Fátima Trinchão. Black female writing. Decoloniality.

\section{INTRODUÇÃO}

Uma mulher negra diz que ela é uma mulher negra, uma mulher branca diz que ela é uma mulher, um homem branco diz que é uma pessoa (KILOMBA, 2016, p. 8).

Maria de Fátima Conceição Trinchão de Carvalho é natural de Euclides da Cunha - BA e reside em Salvador. É poeta e escritora de contos, crônicas, cordéis e dramaturgia. Em seus textos, Fátima Trinchão costuma enfocar temas de cunho social, histórico e psicológico. A escritora tem seus trabalhos publicados na mídia impressa, mas também posta seus textos em blog $^{2}$, uma mídia que vem se constituindo potente para possibilitar a publicação e a circulação da produção literária de vários escritores contemporâneos, em meio a um mercado editorial nem sempre acessível, sobretudo para escritoras negras e nordestinas. No perfil de Fátima Trinchão, no site das escritoras negras da Bahia", há a seguinte declaração da escritora: "Nasci em uma família que amava a poesia, a literatura, o conhecimento. Através do incentivo deles, encontrei na poesia e na literatura o campo propício para desabrochar" (grifo nosso).

É, então, a partir dos vários sentidos que palavra "desabrochar" nos traz - abrir, transformar, nascer, surgir, constitui-se (HOUAISS, 2001), que a escrita de Fátima Trinchão

\footnotetext{
${ }^{1}$ Doutoranda pelo Programa de Pós-Graduação em Literatura e Cultura (PPgLitCult) da Universidade Federal da Bahia (UFBA), e-mail: elianasvieira@yahoo.com.br

2 https://escritorasnegras.com.br/escritora/fatima-trinchao/ Acesso em: 23 maio 2018.
} 


\section{$=$ TRAMA $=$}

será aqui observada. Trata-se da produção de uma mulher negra que deixa de ser objeto da literatura canônica da classe dominante para produzir literatura, para proferir conhecimento, o qual tradicionalmente só é legitimado quando reflete os interesses de uma sociedade branca, colonial e patriarcal.

Desse modo, o presente texto se propõe a analisar a produção literária da escritora negra baiana Fátima Trinchão, como uma prática de (r)existência, com base nos estudos sobre feminismo negro. Seu discurso é, aqui, estudado pelo viés do pensamento decolonial, o qual questiona a centralidade da construção do conhecimento único e exclusivamente da perspectiva do branco cristão ocidental.

Nesse sentido, a pedagoga e ex-ministra das Mulheres, da lgualdade Racial e dos Direitos Humanos Nilma Nilo Gomes (2009) defende que a produção dos intelectuais negros possibilita a construção de um conhecimento pautado não mais no olhar do "outro", do intelectual branco comprometido (ou não) com a luta anti-racista, mas pelo olhar crítico e analítico do próprio negro como pesquisador da temática racial. Trata-se de uma análise e leitura crítica de alguém que tem essa vivência em sua trajetória pessoal e coletiva, inclusive, nos meios acadêmicos. Para a ativista, um dos maiores desafios do intelectual negro talvez seja a sua capacidade e coragem de romper com estruturas opressoras, de construir novas categorias analíticas e literárias através da criação, assumindo a sua própria voz, a sua fala, a sua cultura e a do seu grupo étnico-racial. Constituindo-se, assim, em um sujeito que explicita o seu pertencimento a um grupo historicamente excluído do lugar de produtor da ciência e que carrega esse mesmo grupo na sua voz, no seu corpo, na sua forma de ler, interpretar e produzir conhecimento (GOMES, 2009).

Nessa mesma perspectiva de descolonizar o conhecimento, a escritora e performer portuguesa Grada Kilomba (2016) aponta como o conceito de conhecimento está intimamente relacionado a raça, gênero e poder, e como a epistemologia ocidental definiu não somente como, mas também quem produz conhecimento verdadeiro e em quem acreditarmos. Assim, na estrutura social e hierárquica originada pelo colonialismo, as pessoas negras são silenciadas e suas produções de conhecimento sempre são consideradas como específicas, subjetivas, pessoais, emocionais, parciais e desviantes, ao passo que o discurso branco foi estabelecido como norma. E para as mulheres negras, esse silenciamento toma uma dimensão maior, devido ao pensamento sexista, que reduziu a mulher a um ser desprovido de capacidade para pensar, dificultando, historicamente, seu acesso às esferas de produção do conhecimento.

Conforme expõem os historiadores Wlamyra de Albuquerque e Walter Fraga Filho (2006), a escravidão foi muito mais do que um sistema econômico, ela moldou condutas, definiu desigualdades sociais e raciais, forjou sentimentos, valores e etiquetas de mando e obediência. A partir dela instituíram-se os lugares que os indivíduos deveriam ocupar na sociedade, quem mandava e quem devia obedecer. E nessa hierarquia, como bem observa Grada Kilomba (2016), na epígrafe que abre essa reflexão, a condição da mulher negra é inferior a de qualquer outro grupo.

$\mathrm{Na}$ discussão sobre o legado da escravatura para as mulheres negras, Ângela Davis (2013) afirma que as mulheres eram vistas, assim como os homens, como unidades rentáveis de trabalho, não tendo distinção de gênero nas preocupações dos donos de escravos. Considerando a ideologia de feminilidade, vigente no século XIX, que enfatizava os papéis de mães cuidadoras, companheiras dóceis e donas de casas para os seus maridos, as mulheres negras eram praticamente uma anomalia, já que as mulheres escravas eram primeiro trabalhadoras a tempo inteiro para o seu dono e depois apenas incidentalmente uma esposa, uma mãe, uma dona de casa. 


\section{$=$ TRAMA $=$}

Para além dessa exploração da mão-de-obra comum aos escravos homens e às mulheres escravas, ainda segundo Ângela Davis (2013), as mulheres também sofreram de maneiras diferentes, na medida em que eram vítimas de abuso sexual e outras barbaridades de maus tratos que apenas podem ser infligidas a elas. Assim, as escravas eram igualadas aos homens como trabalhadoras, mas também podiam ser exploradas, castigadas e reprimidas em formas ajustadas apenas às mulheres, sendo fechadas dentro do seu exclusivo "papel feminino".

Foi dessa consciência da inter-relação entre sexo, raça e classe que surgiu o movimento do feminismo negro, a partir do entendimento de que há diferenças no modo como as mulheres brancas e as mulheres negras sofrem a opressão sexista, bem como existem especificidades na maneira como mulheres negras e homens negros são discriminados racialmente. É da ciência desses preconceitos vividos pelas mulheres negras, que tiveram um passado histórico marcado pelo trabalho duro com os seus homens e pela resistência às chicoteadas e à violação, que emergem propostas como a feminista negra estadunidense bell hooks ${ }^{4}$ (2015), quando propõe um feminismo moldado por mãos pretas, que esteja atento à supremacia branca como estratégia, ao impacto psicológico da classe e à condição política dentro de um Estado racista, sexista e capitalista.

Nessa mesma direção, a filósofa, escritora e ativista negra Sueli Carneiro (2003) traz a proposta de enegrecer o feminismo, a partir desse mesmo entendimento de que as mulheres negras tiveram essa experiência histórica diferenciada que o discurso clássico sobre a opressão da mulher não tem reconhecido, bem como não tem considerado o efeito que essa violência sofrida no período escravocrata teve e ainda tem na identidade feminina das mulheres negras. Em seus termos, a violação praticada pelos senhores brancos contra as mulheres negras durante o período escravocrata origina todas as construções de nossa identidade nacional, estruturando o mito da democracia racial latino-americana. Assim, diante dessa consideração de Carneiro (2003), surge o interesse em analisar como os poemas "O canto da chibata", "Saudades da terra", "Mulheres negras mulheres" e "Ecos do passado", publicados no perfil da escritora Fátima Trinchão, no site Recanto das Letras, rememoram o período da escravidão.

A literatura, no entendimento da escritora Conceição Evaristo é um espaço em que os negros podem reivindicar ou afirmar o direito à memória. Ainda que o texto memorialístico rememore uma dor que ainda não foi expurgada, ele não é escrito só com lamentação, ele também traz uma situação de resiliência: "sobrevivemos, inclusive para contar essa memória" (EVARISTO, 2017).

Desse modo, para uma proposta de reflexão acerca das consequências que o período escravocrata ainda traz para o povo negro, é significativo atentar para o fato de que os negros nem como pessoas foram considerados na empresa colonial. Ao refletir sobre a situação do negro à época do colonialismo, que foi retirado de seu contexto social, afastado de sua nação, de seu lugar na família, no trabalho, no poder político, na hierarquia social, religiosa, militar, o estudioso Marco Aurélio Luz (2011) caracteriza a desculturação e repressão ideológica sofridas pelo negro. Do ponto de vista econômico, esse grupo racial foi apenas considerado força de trabalho a ser explorada; do ponto de vista jurídico-político, não possuía nenhum direito, foi classificado como semovente, isto é, equiparado a bois e cavalos; e do ponto de vista ideológico, foi representado como boçal, rude, primitivo. Assim, a ideologia oficial dominante legitimou a classificação jurídica e justificou não só a dominação econômica, mas também a política, a cultural e a étnica. E, mesmo apesar da proclamação da independência, o Brasil

\footnotetext{
${ }^{4}$ bell hooks é o pseudônimo de Gloria Jean Watkins. A feminista opta por registrá-lo em letras minúsculas para dar enfoque ao conteúdo da sua escrita e não à sua pessoa.
} 


\section{$=$ TRAMA $=$}

permaneceria neocolonizado, sendo o colonialismo interno até hoje uma realidade, a qual está representada em inúmeras ideologias teóricas que negam o direito de existência própria de diversos povos e etnias que compõem o Brasil e que aspiram a uma maior e significativa participação na sociedade oficial nacional.

Essas ideologias, ainda conforme Luz (2011), formam as bases teóricas do estereótipo com que são representados e percebidos, na sociedade oficial, o índio, o negro e outros povos não-brancos. Assim, as culturas não dominantes, com sua riquíssima visão sagrada do mundo, com suas formas específicas de comunicação, sua dimensão estética peculiar, seus conhecimentos científicos, de medicina, de matemática, de botânica, seu saber filosófico, psicológico e pedagógico, sofrem a ação de recalcamento dos estereótipos, os quais têm por característica "justificar a exploração e a opressão pelo índice imaginário de superioridade de um grupo humano sobre outro, recalcando todo o processo histórico que engendrou esta situação" (LUZ, 2011, p. 24). E a literatura, sendo produzida majoritariamente pela classe dominante, tem, historicamente, reproduzido esses estereótipos.

Assim, torna-se importante pensar como o período da escravidão está sendo representado na literatura produzida no lugar de fala dos subalternizados. Nos termos da antropóloga e feminista negra Lélia Gonzales, os negros estão na lata de lixo da sociedade brasileira, pois assim o determina a lógica da dominação. Mas, agora, "o lixo vai falar, e numa boa" (GONZALES, 1984, p. 225). De acordo Gilles Deleuze (2004), trata-se da literatura como enunciação coletiva de um povo menor, ou de todos os povos menores, que por intermédio do escritor e nele próprio, encontra a sua expressão.

Conforme aponta Grada Kilomba (2016), o passado colonial está memorizado de tal maneira, que se torna impossível esquecê-lo; é algo que não se pode esquecer e não se consegue evitar lembrar. Não se pode esquecer, porque as vozes negras não podem continuar sendo silenciadas por um sistema racista: "ser ouvida também significa pertencer" (KILOMBA, 2016, p. 3). Então, é a hora de o negro ser ouvido e resgatar o estatuto de ser humano que the tem sido negado desde o período colonial.

No poema "O canto da chibata", Fátima Trinchão escreve, na $1^{\mathrm{a}}$ e $2^{\mathrm{a}}$ estrofes:

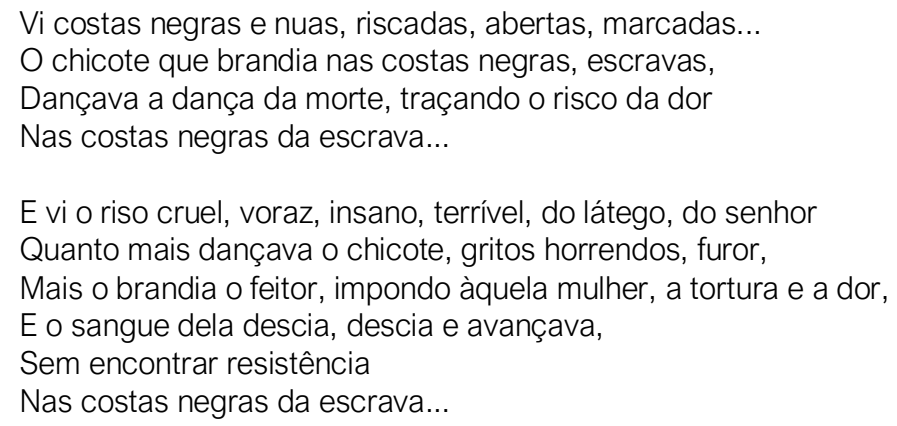

Rememorar o soar da chibata no lombo dessa escrava nos ajuda a entender as atuais chicotadas que as mulheres negras ainda recebem em suas costas. Mesmo livres dos castigos físicos do Senhor, hoje, muitas mulheres negras ainda trabalham arduamente, como burros de cargas, sobretudo em serviços domésticos, durantes horas a fio. Muitas vezes, sem remuneração, apenas em troca de dormir em uma casa "de família" e se de alimentar parcamente, às vezes das sobras. Serve também para pensarmos nas mulheres negras que conseguem, quase sempre por meio dos estudos, adentrar nos espaços que antes eram das brancas, mas que sempre são confundidas com faxineiras ou prostitutas. Trata-se de uma dor ainda não cicatrizada, conforme é descrita na última estrofe de "Saudades da terra": 


\title{
$=\mathrm{T} R A M A=$
}

A dor que é forte e neutraliza, a dor que perene se faz, nas fácies lágrimas amargas, que não cicatrizam jamais, a provocar-lhes lembranças, da porta do nunca mais.

Nunca mais, nunca mais!

Não há mais cicatrizes de chicotadas nas costas dos negros, mas temos diversas mulheres negras vivendo solitárias, com seus corpos marcados por não atenderem a um padrão de beleza branco, ou sendo rotulados como sempre disponíveis sexualmente. E "o riso cruel, voraz, insano, terrível, do látego, do senhor" continua, ainda que no canto da boca, daqueles que impõem essas situações de opressão e discriminação ao povo negro.

Hoje ainda muitos corpos de mulheres negras sucumbem, como o da jovem escrava representada em "O canto da chibata":

\section{Vão-lhe as forças derradeiras, Dessa forma o corpo exangue, No pelourinho, arreia-se. \\ Nele não há mais vida!}

Sucumbem quando não têm oportunidades de driblar a perversidade do sistema capitalista, racista e sexista, quando são exploradas ou por subempregos braçais, ou sexualmente, ou até quando veem a vida dos seus filhos ser ceifada pela repressão policial, ou pela ação de traficantes. Mas, que importância tem um corpo de um filho negro estendido no chão, se no período escravocrata, as escravas eram consideradas como "breeders" 5 , em oposição de "mães", e as suas crianças podiam ser vendidas para longe delas como se vendiam as crias de animais?

Em "Mulheres negras mulheres", Fátima Trinchão rememora a dor das mães que viam seus filhos serem levados ao pelourinho:

\author{
Mulheres negras mulheres \\ Mães da humanidade, \\ Mulheres negras mulheres \\ Que alimentaram com \\ O sangue do seu peito \\ Muito ingrato sinhozinho, \\ Mulheres negras mulheres \\ férteis e corajosas, \\ Mulheres negras mulheres \\ Seus filhos levaram, \\ Levaram, \\ Ao pelourinho, ao açoite, \\ Mulheres negras mulheres \\ Consoladas pelo negror da noite, \\ Pobres mulheres negras \\ Filhas desterradas da África \\ Grande Mãe (...)
}

À mulher negra sempre é difícil o ato de maternar, pois, para além da opressão sexista que impõe às mulheres que o cuidado do filho é exclusivo do universo feminino, as mulheres

\footnotetext{
${ }^{5}$ Durante o século XIX, a popular exaltação ideológica da maternidade não se estendia às escravas. Aos olhos dos donos de escravos, as escravas não eram mães em absoluto; eram simplesmente instrumentos que garantiam o crescimento da força de trabalho escravo. Eram "fazedoras de nascimentos/breeders"- animais, cujo valor monetário podia ser calculado precisamente em função da sua habilidade em multiplicar os seus números (ALBUQUERQUE; FRAGA FILHO, 2006).
} 
negras, muitas vezes, são as únicas provedoras do sustento familiar e criam seus filhos sem o apoio financeiro e afetivo de um companheiro. Quando não são criadas pelas avós, essas crianças se criam sozinhas ou por irmãos mais velhos, tal como suas ancestrais que "muitas vezes levavam para as ruas os filhos pequenos presos às costas ou, quando mais crescidos, mantinham-nos próximos aos locais em que trabalhavam" (ALBUQUERQUE; FRAGA FILHO, 2006, p. 83).

Entretanto, enquanto muitos corpos negros ainda são vencidos, outros resistem, não se deixam dominar. Assim, Fátima Trinchão encerra o já citado poema "O canto da chibata", nos lembrando que esse sangue, o sangue da resistência, não foi derramado em vão:

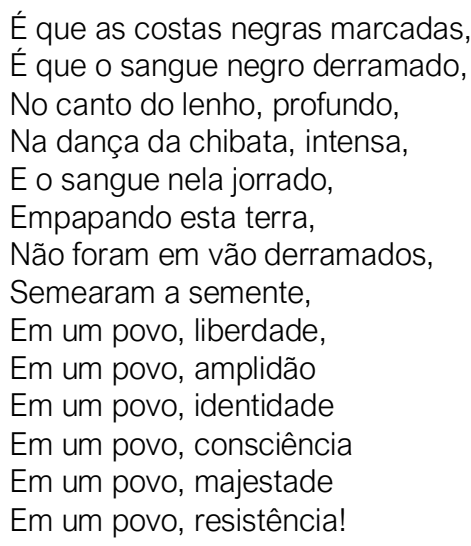

Conforme aponta Jeanne Marie Gagnebin (2006), o ato de rememorar não consiste somente em não se esquecer do passado, mas também compreende uma atenção precisa ao presente, principalmente a estas estranhas ressurgências do passado no presente. No poema "Ecos do passado", Fátima Trinchão nos fala, mais uma vez, dessa resistência negra, que serve de base aos discursos decoloniais:

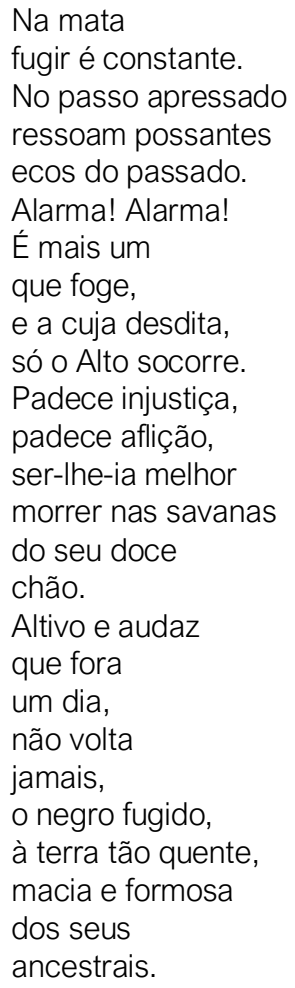




\section{$=$ TRAMA $=$}

Assim, se é potente lembrar e nunca esquecer o som da chibata que ressoou nas costas dos(as) ancestrais africanos(as) para entender o presente ainda marcado pela subalternização da população negra, também é relevante recordar a resistência do negro, com vistas a lutar, superando cada vez com mais eficácia as reminiscências desse passado, e tentar transformar o futuro.

Sobre a produção poética de Fátima Trinchão, a estudiosa Ana Rita Santiago da Silva (2009) considera que suas memórias poéticas são constituídas de representações coletivas de papéis e não apenas de traços individuais, ou seja, em que eventos históricos também são relevantes no processo de (re) elaborações de memórias.

Segundo Jacques Le Goff (1990, p. 476), a memória "é um elemento essencial do que se costuma chamar identidade, individual ou coletiva, cuja busca é uma das atividades fundamentais dos indivíduos e das sociedades de hoje, na febre e na angústia". Ele considera que a memória coletiva faz parte das grandes questões das sociedades desenvolvidas e das sociedades em vias de desenvolvimento, das classes dominantes e das classes dominadas, lutando todas pelo poder ou pela vida, pela sobrevivência e pela promoção.

Assim, entendendo a memória coletiva como um instrumento e um objeto de poder (LE GOFF, 1990), percebe-se, a partir da análise dos poemas aqui selecionados, que a escrita de Fátima Trinchão constitui-se em uma escrita de si que abarca o coletivo, criando memórias individuais e coletivas, rememorando as vivências passadas dos negros, bem como refletindo sobre as suas atuais lutas enfrentadas cotidianamente. É a escrita de uma mulher negra que deseja falar para os negros, conforme declara a escritora: "[...] gostaria principalmente que o 'eu público leitor' fosse o povo negro; fossem todos, mas, de maneira especial, o povo negro, ao qual mando alguns recados e gostaria que fossem captados, entendidos" (TRINCHÃO, 2008, apud SANTIAGO, 2012, p. 80).

Pensando nesses "recados" que Fátima Trinchão tem a dar aos seus, a escrita dos poemas aqui analisados pode ser compreendida como uma reescrita do processo de escravização, a partir de uma fala não autorizada. É um discurso que escova a história a contrapelo, conforme a perspectiva de Walter Benjamin (2012) e procura contar outras histórias, para além da história proposta pelo pensamento ocidental, imposta pelos colonizadores e absorvida pelos colonizados ao longo dos séculos.

Escrever sobre esse período cruel da história brasileira, que ainda ressoa sob a forma do preconceito racial na vida dos afro-brasileiros, a partir de um lugar de fala de quem é oprimido, contribui no processo de construção/reconstrução das identidades do negro. Afirmar identidades, conforme assinala Tomaz Tadeu da Silva (2013), significa demarcar fronteiras, significa fazer distinções entre o que fica dentro e o que fica fora. E os negros têm, historicamente, ficado de fora nessa distinção que afirma e reafirma as relações de poder. Compreende-se, portanto, a escrita de Fátima Trinchão, e na perspectiva do coletivo, a escrita das mulheres negras, como um ato que engendra contra-poderes ou micro-poderes, consoante a concepção de Michel Foucault (2015). É a produção de um discurso que desconstrói e relativiza a hegemonia ocidental, fazendo com que outras vozes ocupem o centro da construção do conhecimento.

Nessa perspectiva, é importante marcar a categoria literatura feminina negra, "uma literatura hifenizada", nos termos de Eurídice Figueiredo (2013, p.150), cujo objetivo é dar maior visibilidade e colocar na agenda nacional a presença daqueles que sempre estiveram marginalizados no espaço público. Nas palavras de Ana Rita Santiago da Silva (2010), a categoria conceitual literatura afro-feminina é "mais uma oportunidade de trazer à baila a necessidade de coalizões a uma escritura que se quer imaginária, mas também comprometida 


\section{$=\mathrm{T} R A M A=$}

com ideais emancipatórios, antipatriarcais e antirracistas, permeando a produção literária" (SILVA, 2010, p. 28).

Desse modo, a escrita de Fátima Trinchão é considerada como um ato de insubordinação, tal como a escritora Conceição Evaristo (2007) entende a escrita das mulheres negras: "A nossa escrevivência não pode ser lida como histórias para 'ninar os da casa grande' e sim para incomodá-los em seus sonos injustos". Nas palavras de Evaristo, "o fazer literário das mulheres negras, para além de um sentido estético, busca semantizar um outro movimento a que abriga todas as nossas lutas. Toma-se o lugar da escrita, como direito, assim como se torna o lugar da vida" (EVARISTO, 2007, p. 54).

Assim, o estudo dos poemas de Fátima Trinchão, aqui selecionados, propiciou o entendimento de como sua escrita (re)significa as memórias da escravidão. Seus textos provocam uma rasura necessária na memória do passado da escravidão, um borrão na história que sempre foi contada a partir da perspectiva do colonizador. É uma escrita de dor, mas também de luta e de protagonismo do povo negro, constituindo-se em um ato de rememoração que se reveste, conforme aponta Márcia dos Santos (2007), de uma intencionalidade que para além da perspectiva de "conhecer o passado", reconstruí-lo, delimita também ações e reações necessárias ao exercício político, seja ele individual ou coletivo, marcando identidades e lutas.

\section{REFERÊNCIAS}

ALBUQUERQUE, Wlamyra R. de; FRAGA FILHO, Walter. Uma história do negro no Brasil. Salvador: Centro de Estudos Afro-Orientais; Brasília: Fundação Cultural Palmares, 2006. Disponível em:

<https://www.geledes.org.br/wp-content/uploads/2014/04/uma-historia-do-negro-no-brasil.pdf >. Acesso: 13 ago. 2018.

BENJAMIN, Walter. Sobre o conceito da história. In: ____ Magia e técnica, arte e política: ensaios sobre literatura e história da cultura - Obras Escolhidas, Volume I. Trad. Paulo Sérgio Rouanet - 8. ed. - São Paulo: Brasiliense, 2012, p. 241-252.

CARNEIRO, Sueli. Enegrecer o feminismo: a situação da mulher negra na América Latina a partir de uma perspectiva de gênero. In Ashoka Empreendimentos Sociais \& Takano Cidadania (Orgs.). Racismos contemporâneos. Rio de Janeiro: Takano Editora, 2003, p. 49-58. Disponível em:

<https://pt.scribd.com/document/322208263/Sueli-Carneiro-Enegrecer-o-Feminismo>. Acesso em: 28 maio 2018.

DAVIS, Ângela. O legado da escravatura: bases para uma nova natureza feminina. In: Mulher, Raça

e Classe. Tradução Livre. Plataforma Gueto, 2013. Disponível em:

<https://we.riseup.net/assets/165852/mulheres-rac3a7a-e-classe.pdf>. Acesso em: 23 maio 2018.

DELEUZE, Gilles. A literatura e a vida. In:__. Crítica e clínica. São Paulo: Editora 34, 2004. p. 11-16.

EVARISTO, Conceição. Conceição Evaristo: minha escrita é contaminada pela condição de mulher negra.

Nexo Jornal, São Paulo, 26 maio 2017. Entrevista concedida a Juliana Domingos de Lima. Disponível em:

<https://www.nexojornal.com.br/entrevista/2017/05/26/Concei\%C3\%A7\%C3\%A3o-Evaristo-

\%E2\%80\%98minha-escrita-\%C3\%A9-contaminada-pela-condi\%C3\%A7\%C3\%A3o-de-mulher-

negra\%E2\%80\%99>. Acesso: 13 ago. 2018.

EVARISTO, Conceição. Da grafia-desenho de minha mãe, um dos lugares de nascimento de minha escrita. In: ALEXANDRE, Marcos Antônio (org). Representações performáticas brasileiras: teorias, práticas e suas interfaces. Belo Horizonte: Mazza Edições, 2007, p 16-21. Disponível em:

$<$ http://nossaescrevivencia.blogspot.com/2012/08/da-grafia-desenho-de-minha-mae-um-dos.html>. Acesso: 13 ago. 2018.

FIGUEIREDO, Eurídice. Mulheres ao espelho: autobiografia, ficção, autoficção. Rio de Janeiro: EdUERJ, 2013. FOUCAULT, Michel. Microfísica do poder. Trad. de Roberto Machado. 2. ed. Rio de Janeiro: Paz e Terra, 2015.

GAGNEBIN, Jeanne Marie. Memória, história, testemunho. In: Lembrar escrever esquecer. São

Paulo: Ed. 34, 2006, p. 49-57. Disponível em:

$<$ https://joaocamillopenna. files.wordpress.com/2015/03/gagnebin-jeanne-marie-lembrar-escreveresquecer.pdf>. Acesso: 25 maio. 2014.

GOMES, Nilma Lino. Intelectuais Negros e Produção do Conhecimento: algumas reflexões sobre a realidade brasileira. In: SANTOS, Boaventura de Sousa; MENESES, Maria Paula. (Orgs.) Epistemologias do Sul.

Coimbra: Edições Almedina. AS, 2009, p. 419-441. Disponível em: <http://cvc.instituto-

camoes.pt/conhecer/biblioteca-digital-camoes/pensamento-e-ciencia/2106-2106/file.html>. Acesso em: 27 maio 2018. 


\section{$=\mathrm{T} R A M A=$}

GONZALEZ, Lélia. Racismo e sexismo na cultura brasileira. In: Revista Ciências Sociais Hoje, Anpocs, 1984, p. 223-244. Disponível em:

<https://edisciplinas.usp.br/pluginfile.php/4130749/mod_resource/content/1/Gonzalez.Lelia\%281983original\%29.Racismo\%20e\%20sexismo\%20na\%20cultura\%20brasileira_1983.pdf>. Acesso em: 28 maio 2018.

HOOKS, bell. Mulheres negras: moldando a teoria feminista. In: Revista Brasileira de Ciência Política, n¹6. Tradução de Roberto Cataldo Costa. Brasília, janeiro - abril de 2015, pp. 193-210. Disponível em: $<$ http://www.scielo.br/pdf/rbcpol/n16/0103-3352-rbcpol-16-00193.pdf >. Acesso em: 23 maio 2018. HOUAISS, Antônio. Dicionário Houaiss da Língua Portuguesa. Rio de Janeiro, Ed. Objetiva, 2001. KILOMBA, Grada. Descolonizando o conhecimento: uma palestra-performance de Grada Kilomba. 2016. Tradução: Jessica Oliveira. Disponível em: <http://www.goethe.de/mmo/priv/15259710-STANDARD.pdf>. Acesso em: 6 de jun de 2018.

LE GOFF, Jacques. Memória. In: ___ História e memória. Tradução Bernardo Leitão et al. Campinas: EDUNICAMP, 1990, p. 423-483. (Coleção Repertórios) Disponível em: < http://memorial.trt11.jus.br/wpcontent/uploads/Hist\%C3\%B3ria-e-Mem\%C3\%B3ria.pdf>. Acesso em: 20 maio 2014.

LUZ, Marco Aurélio. Cultura negra e ideologia do recalque. 3. ed. Salvador: EDUFBA; Rio de Janeiro:

PALLAS, 2011.

SANTIAGO, Ana Rita. Vozes literárias de escritoras negras. Cruz das Almas/BA: UFRB, 2012. Disponível em: <https://www1.ufrb.edu.br/editora/component/phocadownload/category/2-e-books?download=19:vozesliterarias-de-escritoras-negras>. Acesso em: 27 maio 2018.

SANTOS, Márcia Pereira dos. História e memória: desafios de uma relação teórica. In: OPSIS - Revista do Núcleo Interdisciplinar de Pesquisa e Estudos culturais, v.7, n.9, 2007, p. 81-97. Disponível em: <http://www.revistas.ufg.br/index.php/Opsis/article/viewFile/9331/6423>. Acesso em: 25 maio. 2014.

SILVA, Ana Rita Santiago da. Literatura de autoria feminina negra: (des)silenciamentos e ressignificações. Vertentes \& Interfaces I: Estudos Literários e Comparados. Fólio - Revista de Letras, Vitória da Conquista, v. 2, n. 1 p. 20-37, jan./jun. 2010. Disponível em:<

http://periodicos.uesb.br/index.php/folio/article/viewFile/38/276>. Acesso em: 28 abr. 2018.

SILVA, Ana Rita Santiago da. O tear de memórias na poética de escritoras negras baianas. In: LEÃO, Allison; CAVALHEIRO, Juciane \& RIOS, Otávio. Colóquio Nacional Poéticas do Imaginário da Cátedra Amazonense de Estudos Literários: literatura, história, memória. Manaus, AM: UEA Edições, 2009, p. 22-36. Disponível em: $<$ http://www.pos.uea.edu.br/data/area/download/download/51-1.pdf>. Acesso em: 23 maio 2018.

SILVA, Tomaz Tadeu da. A produção social da identidade e da diferença. In: (org.); HALL, Stuart; WOODWARD, Kathryn. Identidade e diferença: a perspectiva dos estudos culturais. 13. ed. Petrópolis, RJ: Vozes, 2013, p. 73-102.

TRINCHÃO, Fátima. Ecos do passado. Disponível em: <http://www.fatimatrinchao.net/>. Acesso em: 23 maio 2018.

TRINCHÃO, Fátima. Mulheres negras mulheres. Disponível em: <http://www.fatimatrinchao.net/>. Acesso em: 23 maio 2018.

TRINCHÃO, Fátima. O canto da chibata. Disponível em: <http://www.fatimatrinchao.net/>. Acesso em: 23 maio 2018

TRINCHÃO, Fátima. Saudades da terra. Disponível em: <http://www.fatimatrinchao.net/>. Acesso em: 23 maio 2018. 